\title{
Fracture behaviour of MOD restorations reinforced by various fibre-reinforced techniques - An in vitro study
}

(i) The corrections made in this section will be reviewed and approved by journal production editor.

Tekla Sárya ${ }^{a}$ Sufyan Garoushi ${ }^{\mathrm{b}}$, Gábor Braunitzerc ${ }^{\mathrm{c}}$, David Alleman ${ }^{\mathrm{d}}$, András Volomª , Márk Fráter $^{\mathrm{a},{ }^{*}}$ meddentist.fm@gmail.com

aDepartment of Operative and Esthetic Dentistry, Faculty of Dentistry, University of Szeged, Szeged, Hungary

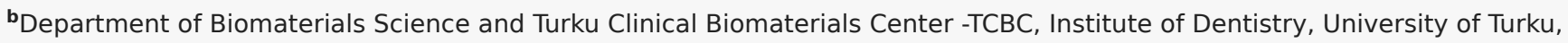
Turku, Finland

'DicomLAB Dental Ltd., Szeged, Hungary

dThe Alleman Center for Biomimetic Dentistry, Utah, USA

*Corresponding author. Department of Operative and Esthetic Dentistry Faculty of Dentistry, University of Szeged, Tisza Lajos Krt. 64-66, H-6720, Szeged, Hungary.

\begin{abstract}
Purpose :The aim was to evaluate the fracture resistance of various direct restorative techniques utilizing different fibre-reinforced materials for restoring deep class II. MOD cavities in molar teeth.

Material and methods :Two hundred forty intact mandibular third molars were randomly divided into twelve groups $(n=20)$. Except for the control group (G12), deep mesio-occluso-distal (MOD) cavities were prepared all other groups. After adhesive treatment and rebuilding the missing interproximal walls with composite, the specimen were restored with different fibres and a final occlusal layer of composite as follows: composite only (G1), short fibrereinforced composite (SFRC) (G2), glass fibre net (GFN) on the base of the cavity bucco-lingually (BL) and SFRC (G3), SFRC and GFN on top of it BL (G4), SFRC and occlusal splinting with GFN (G5), GFN circumferentially and SFRC (G6), polyethylene fibres (PF) on the base of the cavity $B L$ and composite (G7), composite and PF on top of it BL (G8), composite and occlusal splinting with PF (G9), PF circumferentially and composite (G10), transcoronal splinting with PF (G11). Fracture-resistance for the restored teeth were tested using universal-testing machine. Fracture thresholds and fracture patterns were measured and evaluated.
\end{abstract}

Results :The transcoronal splinting (G11) yielded the highest fracture resistance among the restored groups. Groups 1,3 and 4 showed significantly lower fracture resistance values compared to intact teeth.

Conclusion : Incorporating polyethylene or a combination of short and bidirectional glass fibres in certain positions in direct restorations seems to be able to restore the fracture resistance of sound molar teeth.

Keywords :MOD cavity; Short fibre-reinforced composite; Glass fibre net; Polyethylene; Fracture toughness; Splinting

\section{Introduction}

Placement and replacement of direct restorations belong to the most frequently performed interventions in general dentistry. Given the high patient demand for tooth-colored restorations that make a natural impression, the use of direct posterior composite resin (CR) restorations has widely increased for such purposes (Behery et al., 2016). The number of direct posterior $\mathrm{CR}$ restorations will continue to increase with the worldwide phasedown in the use of amalgam (Ástvaldsdóttir et al., 2015; Kielbassa et al., 2014; FDI World Dental Federation, 2014). In addition to the aesthetic considerations, a restoration must also restore function and preserve the remaining tooth structure against fracture (Taha et al., 2011).

This is highly important in case of large carious defects and subsequent cavities (e.g. mesio-occluso-distal (MOD) cavities). Extensive cavity preparation is one of the primary reasons for tooth fragility, resulting in partial or complete fractures of posterior tooth cusps or even root fractures (Soares et al., 2008). A standardiszed MOD cavity preparation in maxillary premolar teeth was shown to result in $63 \%$ average loss in relative cuspal stiffness (El-Helali et al., 2013), which is related principally to the loss of marginal ridge integrity (Reeh et al., 1989; Wu et al., 2010). This causes a reduction in fracture strength of approximately 54\% (Hannig et al., 2005; Seo et al., 2012). It has been shown that cuspal deflection increases with increasing cavity dimensions (Taha et al., 2009), meaning the larger the restoration's volume, the higher the stress generated in the 
remaining dental structure. This is in accordance with both in vitro and clinical findings, showing that in general, for both molar and premolar teeth, the higher the number of restored surfaces and the wider the isthmus of the restoration, or both, the greater the chance of cuspal fracture with time (de V Habekost et al., 2007). CR restorations have the advantage of bonding to tooth structure, thus theoretically providing an ,internal splint”, which might strengthen the tooth and help regain its lost fracture resistance. However, the reinforcing effect of direct composite fillings alone in deep MOD cavities is highly debated. The increased use of composite materials in the posterior region brought about technological advances as new materials were needed to overcome the shortcomings of conventional composite fillings.

The development of fibre-reinforced composite (FRC) technology allowed the use of CR materials in extensive preparations (Belli et al., 2005). In 2013, a short fibre-reinforced composite (SFRC) (EverX Posterior; GC, Tokyo, Japan) was introduced as a dental restorative CR intended to be used in high-stress-bearing areas in both vital and non-vital teeth, especially in molars (Garoushi et al., 2013a, 2018). As the fibres incorporated into the SFRC have a length equal to or greater than the critical fibre length $(0.5-1.6 \mathrm{~mm})$ (Vallittu, 2015), it is able to act as a stress-absorbing, dentine-replacing material (Garoushi et al., 2018). The randomly oriented fibres in SFRC provide reinforcement in three directions, whereas bidirectional or woven continuous fibres provide reinforcement in only two directions (Başaran et al., 2013). Theoretically, however, the directional distribution of reinforcement is less effective in SFRC, since a certain volume of fibres is divided in three directions (Dyer et al., 2004a). So far continuous bi-directional FRC (EverStick NET; GC, Tokyo, Japan) has been used to reinforce or repair provisional fixed partial dentures (Vallittu, 1998) or reinforce indirect composite restorations by being applied in the intaglio (Vallittu, 2002) or placed under endocrowns (Rocca et al., 2016), but not for direct restorative purposes inside cavities.

Also, in the past 20 years, a leno woven ultra high molecular weight (LWUHMW) polyethylene fibre ribbon (Ribbond THM; Ribbond Inc., Seattle WA, USA), inserted into a bed of flowable composite, have been used in various direct restorative techniques. The purpose of the polyethylene fibres is manifold: partly to form a stress-absorbing layer and redirect potential cracks and fractures (Rudo and Karbhari, 1999), and partly to internally splint the tooth and increase fracture strength (Belli et al., 2005). Application techniques included lining the fibre under the composite filling (Belli et al., 2005, 2006a, 2006b) or over the finished composite restoration by preparing a groove (Belli et al., 2006b) or applying the fibres inside the axial walls circumferentially (Deliperi et al., 2017).

The question arises whether continuous bidirectional FRC could be used in cavities in the same manner as polyethylene fibres and and if they could amplify the reinforcing effect of SFRC.

The purpose of this in vitro investigation was to assess the reinforcing effect of different $\mathrm{FRC}$ materials compared to polyethylene ribbon fibres with conventional composite in direct restorative techniques applied in class II deep MOD cavities.

The null hypothesis was that (1) the teeth restored with the tested restorative techniques would show similar mechanical resistance as intact molar teeth, and that (2) the fracture patterns in molar teeth with deep class II cavities would not depend on the applied restorative technique.

\section{Material and methods}

240 mandibular third molars extracted for periodontal or orthodontic reasons were selected for this study. The freshly extracted teeth were immediately placed in $5.25 \% \mathrm{NaOCl}$ for $5 \mathrm{~min}$ and then stored in $0.9 \%$ saline solution at room temperature until use all within 2 months of extraction. During specimen preparation, the soft tissue covering the root surface was removed with hand scalers. The inclusion criteria were visual absence of caries or root cracks, absence of previous endodontic treatment, posts or crown or resorptions. Teeth with severe polymorphism of the coronal structures were excluded from the investigation.

About eighty percent of the specimens ranged $10.0-10.9 \mathrm{~mm}$ in size, measured at the widest bucco-lingual dimension, and the rest were between 11.0 and $12.0 \mathrm{~mm}$. The mesio-distal dimension of the samples was also measured and this parameter allowed a maximum deviation of $10 \%$ from the determined mean. The teeth were randomly distributed over 12 study groups $(n=20)$ (see below).

\subsection{Cavity preparation and restorative procedures}

One group was left intact to serve as a control (Group 12). The rest of the teeth received standardised MOD cavity preparation with $2.5 \mathrm{~mm}$ wall thicknesses and with $5 \mathrm{~mm}$ depth prepared by the same trained operator as described by Forster et al. (2019). The preparation was performed with a round end parallel diamond (881.31.014 FG - Brasseler USA Dental, Savannah, GA) bur initially positioned at the midline of the occlusal surface of the teeth (determined by dividing the distance between the buccal and lingual cusp tips). The thickness of the opposing walls at the cavity base were continuously checked during the preparation with a digital calliper (Mitutoyo Corp., Kawasaki, Japan) and adjusted to have a uniform $2.5 \mathrm{~mm}$ thickness at the base of the cavity. The cavity walls were prepared parallel to the axis of the tooth. The depth of the cavity was evaluated with a 15 UNC periodontal probe (Hu-Friedy Mfg. Co., Chicago, USA) measured from the corresponding cusp tip by touching the cavity wall with full length of the instrument. The cavity was one continuous cavity with the proximal box having exactly the same width $(2.5 \mathrm{~mm})$ and depth $(5 \mathrm{~mm})$ as the occlusal one. The cavosurface margins were prepared perpendicular to the tooth surface at 
the end of the preparation. Only in Group 11, on both buccal and lingual walls, an artificial whole with a width of approx. 2-3 mm was prepared on the occlusal third of the wall with a diamond micropreparation bur (MP 53, TwoStriper, Airbrasive Tehcnology inc. USA). After the preparation all cavities were rinsed with water and air-dried with an air/water syringe. The cavities received the same adhesive treatment. After application of a Tofflemire (1101C 0.035, Hawe-Neos, Italy) matrix band, the enamel was acid-etched selectively with $37 \%$ phosphoric acid for $15 \mathrm{~s}$, rinsed with water and air-dried. The cavity was adhesive-treated with G-Premio Bond (GC Europe, Leuven, Belgium) according to the manufacturer's instructions. The adhesive layer was light-cured for 40 s with an Optilux 501 halogen light (Kerr, Orange, CA, USA) operating in standard mode at a light intensity of $740 \pm++36$ $\mathrm{mWcm}^{2}$. In all groups, an approximately $0.5 \mathrm{~mm}$-thick flow composite layer (G-aenial Flo, GC Europe, Leuven, Belgium) was applied on the floor of the cavity. This layer was light-cured for $40 \mathrm{~s}$. After applying the flowable, the interproximal walls were build-up with composite (G-aenial Posterior PJ-E, GC Europe, Leuven, Belgium) using the centripetal technique, thus transforming the MOD cavity into a class I. cavity.

From this point the cavities were distributed among 11 groups according to the different direct restorative techniques. The cavities were restored as follows (see Fig. 1.):

Group 1 The cavities were restored with micro hybrid composite restorative material (G-aenial Posterior PJ-E, GC Europe, Leuven, Belgium) applied with an oblique incremental technique. The material was placed in consecutive $2 \mathrm{~mm}$ thick increments. Each increment was light cured from the occlusal surface for 40 s. Glycerine gel (DeOx Gel, Ultradent Products Inc., Orange, CA, USA) was applied and final polymerization from each side for $40 \mathrm{~s}$ with Optilux 501 was performed. The finishing and polishing was the same in all groups, meaning the restoration was finished with a fine granular diamond burr (FG 7406-018, Jet Diamonds, USA and FG 249-F012, Horico, Germany) and aluminum oxide polishers (OneGloss PS Midi, Shofu Dental GmbH, Ratingen, Germany).

Group 2 The cavities were restored with an SFRC material (EverX Posterior, GC Europe, Leuven, Belgium) applied in a bulk-fill technique. The material was placed in single increment according to the anatomy of the dentine, leaving 1,5-2 mm occlusally for the final composite layers as prescribed by the manufacturer. This increment was light cured from the occlusal surface for $40 \mathrm{~s}$. The last occlusal layer was composite material (G-aenial Posterior PJ-E, GC Europe, Leuven, Belgium) covering the SFRC. Glycerine gel (DeOx Gel, Ultradent Products Inc., Orange, CA, USA) was applied and final polymerization from each side for $40 \mathrm{~s}$ with Optilux 501 was performed.

Group 3 A piece of $3 \mathrm{~mm}$ wide pre-impregnated glass fibre net (Everstick NET, GC Europe, Leuven, Belgium) with a size approx. the same as the remaining cavity was cut and placed on the cavity walls in a bucco-lingual direction. The net was placed in a way that it would not reach the margins of the cavity, leaving 1,5-2 mm space for the future occlusal composite layer. In all groups where the net was used, it was adapted to the walls with a periodontal probe (Hu-Friedy Mfg. Co., Chicago, USA) slightly wetted in resin (Stick resin, GC Europe, Leuven, Belgium) and handled according to manufacturer's instructions. After curing for $40 \mathrm{~s}$, the cavity was restored with SFRC and a final layer of occlusal composite as in Group 2.

Group 4 The cavities were restored with SFRC as described in Group 2. When there was only approx. 1.5-2 mm space remaining of the cavity occlusally, a piece of $3 \mathrm{~mm}$ wide pre-impregnated glass fibre net (Everstick NET, GC Europe, Leuven, Belgium) was placed on the cavity walls in a bucco-lingual direction. The net was placed in a way that it would not reach the margins of the cavity. After curing for 40 s, the cavity was restored with a final layer of occlusal composite as in Group 2.

Group 5 The cavities were restored with SFRC and a final layer of occlusal composite as in Group 2. After finishing the restoration, a groove $4 \mathrm{~mm}$ wide and $1,5 \mathrm{~mm}$ depth was prepared on the occlusal surface of the restorations between the cusp tips, from a buccal to lingual direction, with a high speed bur under water cooling. The ends of the groove were on the occlusal one-third of the buccal and lingual walls of the teeth. After selective enamel etching in the mentioned area, the groove was rinsed, dried and adhesively treated (G-Premio Bond, GC Europe, Leuven, Belgium). A piece of pre-impregnated glass fibre net (Everstick NET, GC Europe, Leuven, Belgium) with a size of the prepared groove was cut and placed into the groove. After curing for 40 s, the cavity was restored with a final layer of occlusal composite as in Group 2.

Group 61 piece of $3 \mathrm{~mm}$ wide pre-impregnated glass fibre net (Everstick NET, GC Europe, Leuven, Belgium) was placed on the cavity walls circumferentially. The net was placed in a way that it would cover the axial walls but not reach the margins of the cavity. After curing for 40s, the cavity was restored with SFRC and a final layer of occlusal composite as in Group 2.

Group 71 pieces of $3 \mathrm{~mm}$ wide LWUHMW polyethylene ribbon fibres (Ribbond-Ultra THM; Ribbond Inc., Seattle WA, USA) were placed into the cavity covering the cavity walls in a bucco-lingual direction forming a fibre layer with Ribbond just as in Group 3 with the glass fibre net. In all groups where polyethylene fibres were used, the fibres were first saturated with adhesive resin (Stick Resin, GC Europe, Leuven, Belgium), the excess adhesive resin was removed with a hand instrument and then placed into the bed of un-cured flowable composite (G-aenial universal flo, GC Europe, Leuven, Belgium). The fibre was placed in a way that it would not reach the margins of the cavity. After curing for $40 \mathrm{~s}$, the cavity was restored with microhybrid composite as in Group 1.

Group 8 The cavities were restored with a microhybrid composite applied in an oblique incremental technique. The material was placed in consecutive $2 \mathrm{~mm}$ thick increments. Each increment was light cured from the occlusal surface for $40 \mathrm{~s}$. When there was only approx. $1.5-2 \mathrm{~mm}$ space remaining of the cavity occlusally, 1 piece of $3 \mathrm{~mm}$ wide LWUHMW polyethylene ribbon fibres 
(Ribbond-Ultra THM; Ribbond Inc., Seattle WA, USA) was cut and placed in the remaining cavity in a bucco-lingual direction forming a fibre layer with Ribbond just as in Group 4 with the glass fibre net. After handling of the fibres and curing for 40 s, the cavity was restored with a final layer of occlusal composite as in Group 1.

Group 9 the cavity was restored with microhybrid composite as in Group 1. After finishing the restoration, a groove 4-mm wide and 1-mm depth was prepared on the occlusal surface of the restorations between the cusp tips, from a buccal to lingual direction, with a high speed bur under water cooling. The ends of the groove were on the occlusal one-third of the buccal and lingual walls of the teeth. After selective enamel etching in the mentioned area, the groove was rinsed, dried and adhesively treated (G-Premio Bond, GC Europe, Leuven, Belgium). A piece of LWUHMW polyethylene ribbon fibre (Ribbond-Ultra THM; Ribbond Inc., Seattle WA, USA) was placed into the groove. After handling of the fibres and curing for 40 s, the cavity was restored with a final layer of occlusal composite.

Group 10 A piece of LWUHMW polyethylene ribbon fibre (Ribbond THM; Ribbond Inc., Seattle WA, USA) was cut and placed on the cavity walls circumferentially. The fibre was handled and adapted into flowable composite as in Group 7. After curing for 40 s, the cavity was restored with microhybrid composite as in Group 1.

Group 111 piece of $1 \mathrm{~mm}$ wide LWUHMW polyethylene ribbon fibres (Ribbond Ultra Orthodontic; Ribbond Inc., Seattle WA, USA) were placed through the previously performed penetrations on the buccal and lingual walls into the prepared grooves on the external coronal surfaces connecting the opposing walls like a tightrope. First the polyethylene fibres were fixed in one groove, light cured and covered with composite, and subsequently the rest of the fibres on the opposing side were tightly positioned with a tweezer and fixed to the opposing groove by light curing and composite coverage. This produced a "transcoronal splinting" inside the cavity. After curing for 40s, the cavity was restored with microhybrid composite as in Group 1.

\section{Fig. 1}

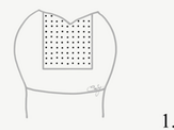

1.

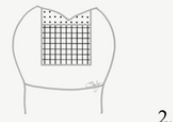

2.

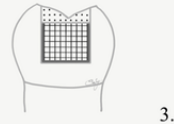

3.
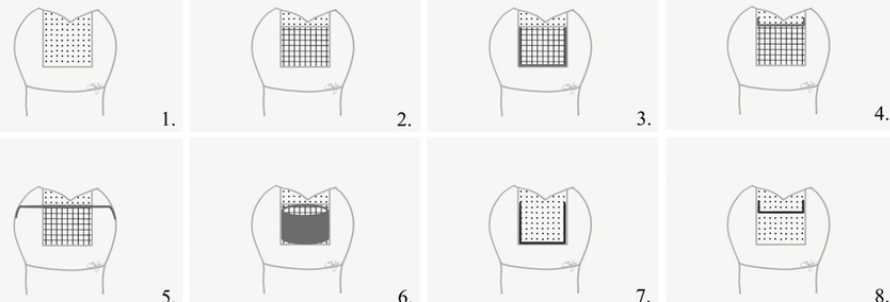

5 .

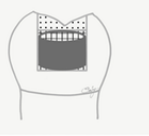

6.

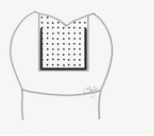

7.
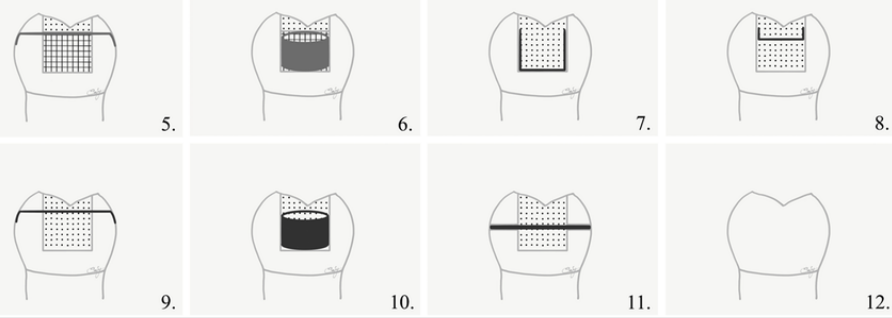

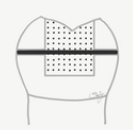

11.

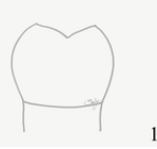

Schematic figure representing the test groups (Group 1-12).

\subsection{Embedding and mechanical testing of specimen}

The restored specimen were stored in physiological saline solution (Isotonic Saline Solution 0.9\%; B. Braun, Melsungen, Germany) in an incubator (mco-18aic; Sanyo, Moriguchi, Japan) at $37^{\circ} \mathrm{C}$. To simulate the periodontal ligament, the root surface of each tooth was coated with a layer of liquid latex separating material (Rubber-Sep, Kerr, Orange, CA) prior to embedding. Specimens were embedded in methacrylate resin (Technovit 4004, Heraeus-Kulzer) at 2 mm from the cementoenamel junction (CEJ) to simulate the bone level. After embedding, all specimens were immediately subjected to a fracture resistance test. Teeth were quasi-statically loaded with a crosshead speed of $2 \mathrm{~mm} / \mathrm{min}$ parallel to the long axis of the tooth in a universal testing machine (5848 MicroTester1, Instron, Norwood, MA, USA) until they were fractured. A cylindrical steel bar $6 \mathrm{~mm}$ in diameter and $10 \mathrm{~mm}$ long was used (Soares et al., 2004; Cobankara et al., 2008). The bar was positioned at the centre of the occlusal surface of the tooth crown between the buccal and oral cusps. A force vs. distance curve was dynamically plotted for each tooth. Failure load-defined as the load at which the tooth-restoration complex exhibited the first fracture, resulting in a peak formation on the force versus distance curve-was recorded in Newtons (N). In each case the specific failure load was determined when the force versus distance curve showed an abrupt change in load, indicating a sudden decrease in the specimen's resistance to compressive loading (Figs. 2-4.). After recording failure load, each specimens were visually examined for the type and location of failure, as well as the direction of failure. According to Scotti and co-workers, distinction was made between restorable or nonrestorable fractures under optical microscope with a two-examiner agreement. A restorable fracture is above the CEJ, meaning that in case of fracture, the tooth can be restored, while a nonrestorable fracture extends below the CEJ and the tooth is likely to be extracted (Scotti et al., 2012). 


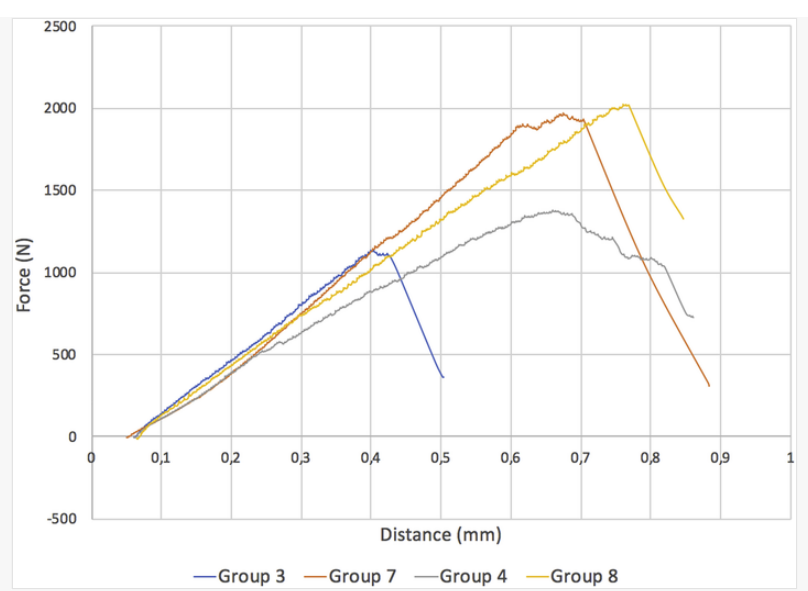

Force versus distance curves of specimens representing each study groups. Peaks indicate the amount of maximal failure load.

\section{Fig. 3}

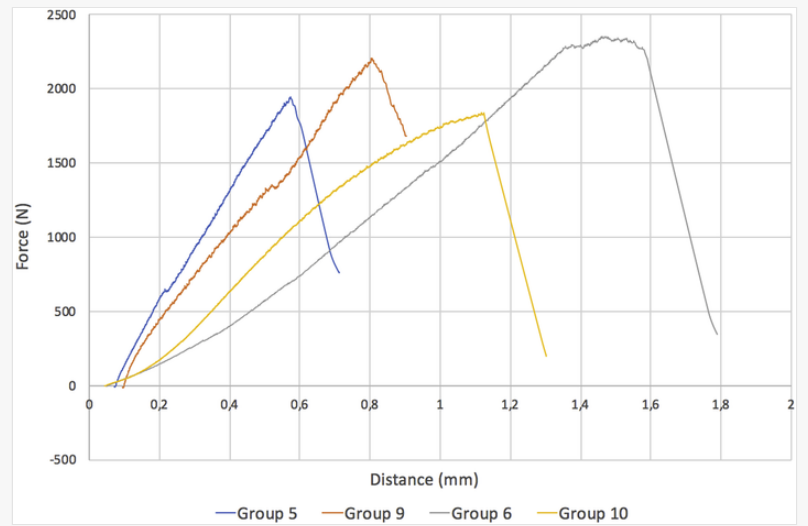

Force versus distance curves of specimens representing each study groups. Peaks indicate the amount of maximal failure load.

\section{Fig. 4}

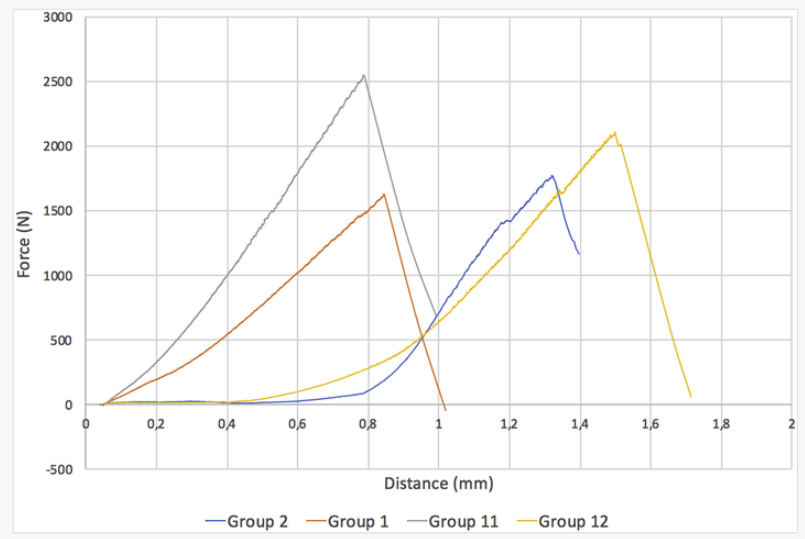

Force versus distance curves of specimens representing each study groups. Peaks indicate the amount of maximal failure load.

\subsection{Statistical analysis}

Statistical analysis was conducted in SPSS 23.0 (SPSS Inc., Chicago, IL). For the comparisons between the groups, ANOVA with Tukey's HSD post-hoc test was used. The general limit of significance was set at $\alpha=0.05$.

\section{Results}

Table 1 summarizes the fracture thresholds for the different study groups. The transcoronal splinting (Group 11) yielded the highest fracture resistance among the restored groups, and interestingly, this was even slightly higher than that of the control 
group (intact teeth). Groups 1, 3 and 4 showed significantly lower fracture resistance values compared to intact teeth, thus the null hypothesis was rejected. The results of the post-hoc pairwise comparisons (Tukey's HSD) are given in Table 2 . In terms of the fracture patterns (Table 3), the type of fibres and their position within the restoration influenced the ratio of favourable and unfavourable fractures. SFRC only (Group 2) was characterised by the highest percentage of favourable (i.e. reparable) fractures, while composite alone (Group 1) and transcoronal splinting (Group 11) yielded the lowest ratio. Therefore, the null hypothesis regarding fracture patterns was also rejected.

alt-text: Table 1

\section{Table 1}

(i) The presentation of Tables and the formatting of text in the online proof do not match the final output, though the data is the same. To preview the actual presentation, view the Proof.

Descriptive statistics of the results by group. Groups: 1- composite; 2- SFRC; 3- net B-L at the bottom; 4- net B-L at the top; 5- net occlusal splinting; 6net circumferential; 7- Ribbond B-L at the bottom; 8- Ribbond B-L at the top; 9- Ribbond occlusal splinting; 10- Ribbond circumferential; 11- Ribbond transcoronal splinting; 12 - control.

\begin{tabular}{|c|c|c|c|}
\hline Group & Mean (N) & $\boldsymbol{N}$ & $S D$ \\
\hline Group 1 & 1629.45 & 20 & 503.11 \\
\hline Group 2 & 1746.25 & 20 & 467.50 \\
\hline Group 3 & 1122.20 & 20 & 440.04 \\
\hline Group 4 & 1408.65 & 20 & 314.59 \\
\hline Group 5 & 1925.60 & 20 & 792.69 \\
\hline Group 6 & 2067.30 & 20 & 535.80 \\
\hline Group 7 & 1834.40 & 20 & 578.56 \\
\hline Group 8 & 2022.05 & 20 & 771.41 \\
\hline Group 9 & 2129.25 & 20 & 629.75 \\
\hline Group 10 & 1906.95 & 20 & 538.09 \\
\hline Group 11 & 2484.80 & 20 & 682.90 \\
\hline Group 12 & 2266.30 & 20 & 601.14 \\
\hline
\end{tabular}

\section{alt-text: Table 2 \\ Table 2}

(i) The presentation of Tables and the formatting of text in the online proof do not match the final output, though the data is the same. To preview the actual presentation, view the Proof.

Significance matrix from the post-hoc pairwise comparisons (Tukey's HSD). The conventions are the same as in Table 1. Empty cells indicate lack of significance.

\begin{tabular}{|c|c|c|c|c|c|c|c|c|c|c|c|c|}
\hline & Group 1 & Group 2 & Group 3 & Group 4 & Group 5 & Group 6 & Group 7 & Group 8 & Group 9 & Group 10 & Group 11 & Group 12 \\
\hline Group 1 & - & & & & & & & & & & 0.000 & 0.033 \\
\hline Group 2 & & - & & & & & & & & & 0.005 & \\
\hline Group 3 & 0.000 & 0.041 & - & & 0.001 & 0.000 & 0.009 & 0.000 & 0.000 & 0.002 & 0.000 & \\
\hline Group 4 & 0.000 & & & - & & 0.0023 & & 0.049 & 0.007 & & 0.000 & \\
\hline Group 5 & & & 0.001 & & - & & & & & & & \\
\hline Group 6 & & & 0.000 & 0.023 & & - & & & & & & \\
\hline Group 7 & & & 0.009 & & & & - & & & & 0.026 & \\
\hline Group 8 & & & 0.000 & 0.049 & & & & - & & & & \\
\hline Group 9 & & & 0.000 & 0.007 & & & & & - & & & \\
\hline Group 10 & & & 0.002 & & & & & & & - & & \\
\hline
\end{tabular}




\begin{tabular}{|l|l|l|l|l|l|l|l|}
\hline Group 11 & & 0.000 & 0.000 & 0.026 & \\
\hline Group 12 & 0.033 & 0.000 & 0.000 & 0.000 & \\
\hline
\end{tabular}

(i) The presentation of Tables and the formatting of text in the online proof do not match the final output, though the data is the same. To preview the actual presentation, view the Proof.

Fracture patterns by group. Numbers of observations and within-group percentages. The conventions are the same as in Table 1.

\begin{tabular}{|l|l|l|l|l|l|l|l|l|l|l|l|l|l|l|}
\hline & G1 & G2 & G3 & G4 & G5 & G6 & G7 & G8 & G9 & G10 & G11 & G12 \\
\hline reparable & $4(20 \%)$ & $16(80 \%)$ & $8(40 \%)$ & $14(70 \%)$ & $13(65 \%)$ & $14(70 \%)$ & $8(40 \%)$ & $10(50 \%)$ & $10(50 \%)$ & $12(60 \%)$ & $4(20 \%)$ & $18(90 \%)$ \\
\hline irreparable & $16(80 \%)$ & $4(20 \%)$ & $12(60 \%)$ & $6(30 \%)$ & $7(30 \%)$ & $6(30 \%)$ & $12(60 \%)$ & $10(50 \%)$ & $10(50 \%)$ & $8(40 \%)$ & $16(80 \%)$ & $2(10 \%)$ \\
\hline
\end{tabular}

\section{Discussion}

With recent advances in adhesive technology and the appearance of stronger composite materials, molar teeth with significant damage or carious lesion are routinely treated by extensive MOD cavity filling (Chai and Lawn, 2017). In this study, deep MOD cavities were restored with various direct restorative techniques. The dimensions of the MOD cavities used in our study are closest to those of a large direct amalgam replacement, which is also becoming common in daily routine (Cara et al., 2007). However, polymerization shrinkage is a serious problem for large direct composite restorations (Plotino et al., 2008; Taha et al., 2011), resulting in cuspal strains with subsequent stress or disruption of the bond, microleakage and recurrent caries, or even enamel cracking (Taha et al., 2011). To minimize the development of stresses, it is important to use incremental placement techniques, in which the layers are polymerized through the cusps. The other inherent problem of composite materials is their inadequate fracture toughness, which was shown to be significantly lower than that of dentine (Deliperi et al., 2017). Fracture within the body (bulk) and margins of restorations and secondary caries have been mentioned as major problems regarding the failure of posterior composites (Lassila et al., 2018; Demarco et al., 2012). As modern composite resin materials are rigid, they do not lack strength, but they lack toughness (Deliperi et al., 2017). As described by Lassilla et al., fracture toughness is a mechanical property that describes the resistance of brittle materials to the catastrophic propagation of flaws under an applied load (Lassila et al., 2018). Thus, it describes damage tolerance of the material and can be considered as a measure of fatigue resistance which predicts structural performance. The problem of lack of toughness is especially well seen in extensive direct restorations, as the volume of the material increases in these cases (Braga et al., 2006). As a result of the above-mentioned disadvantages, direct composite fillings might not be the best solution in deep MOD cavities in posterior teeth. In our study, teeth restored with layered composite fillings (Group 1) showed significantly lower fracture resistance than intact teeth (group 12) $(p=0.033)$. This is in accordance with the results of Förster et al., showing that molar not root canal treated teeth with deep cavities cannot be successfully reinforced with direct composite fillings (Forster et al., 2019). The same was shown by Papadopoulos et al., when they compared the fracture resistance of natural teeth with MOD cavities restored with a bulk-fill composite (Papadopoulos et al., 2018). Scholtanus et al. found that premolar teeth with MOD cavities restored with direct composite fillings were significantly weaker than intact teeth. However, in their study one cusp was also replaced by composite material (Scholtanus and Ozcan, 2014). According to Förster et al., in MOD cavities the depth of the cavity is of critical importance when a direct restorative technique is chosen (Forster et al., 2019). Not only is the cantilever effect greater in deep cavities, but also the volume of the restorative material, which highlights the shortcomings of conventional composite materials. In our study, this problem is reflected both in fracture resistance values and the fracture pattern of teeth restored with CR fillings. Regarding fracture pattern, Group 1 was characterised by predominantly unrestorable fractures. Stressabsorption and crack-arresting ability is attributed to the dentine-enamel junction (DEJ) and to the dentine adjacent to this interphase (Lee et al., 2009). The more structurally compromised the tooth, the lower the proportion of DEJ and sound dentine is, and the higher the chance for catastrophic failure in the restoration-tooth continuum. A material with high fracture toughness can better resist crack initiation and propagation, thus would be ideal to replace the missing DEJ and/or dentine core. SFRC is intended to be used in high-stress-bearing areas and/or in structurally compromised teeth as a dentine replacing material ( Garoushi et al., 2013b). Mechanical testing has shown major improvements in load-bearing capacity, flexural strength and also the fracture toughness of SFRC in comparison with conventional composite resin materials. Bijelic-Donova et al. showed that SFRC had a statistically higher fracture toughness $\left(2.4 \mathrm{MPam}^{1 / 2}\right)$ and fatigue limit than conventional CR resins (range: 0.9$1.1 \mathrm{MPa} \mathrm{m}^{1 / 2}$ ) (Bijelic-Donova et al., 2016). They managed to show a strong correlation between fracture toughness and fatigue performance, with SFRC being able to sustain both compressive static and fatigue load. The toughening ability of SFRC over conventional composites is attributed to two main factors: the millimeter-scale short fibres and the unique semi-IPN structure. In our study, teeth restored with SFRC (Group 2) did not show statistically significant difference from intact teeth (Group 12) in 
terms of fracture resistance. Also, the fracture pattern changed to predominantly favourable fractures, compared to the composite group (Group 1). In fact, the SFRC group produced the highest amount of favourable fractures among the restored groups. This is in accordance with Fráter et al. where SFRC was able to shift the fracture pattern to predominantly favourable even in shallower MOD cavities (Fráter et al., 2014). Several studies have shown that the SFRC substructure supports the composite restoration and serves as a crack-prevention layer (Garoushi et al., 2006a, 2007a, 2007e). The thickness of the SFRC core has utmost importance, as it influences the failure mode and the crack-arresting mechanism (Garoushi et al., 2018). In this study, SFRC was applied in a biomimetic way, substituting the missing dentine and ending at the level of the lost DEJ, in order to substitute both tissues simultaneously, following Monaco et al., who suggested that the highest fracture resistance could be achieved this way (Monaco et al., 2015).

Deep MOD cavities are susceptible to fracture (Hannig et al., 2005), which is mainly caused by the increased cavity dimensions and the loss of marginal ridges (El-Helali et al., 2013), leading to increased cuspal flexure and overall weakening of the tooth ( Taha et al., 2009). In order to stabilize the remaining opposing cavity walls, several direct methods utilizing fibres as internal connecting or splinting elements have been put forward. So far, reinforcement with fibres has been shown to enhance strength only in a narrow range of dental materials, such as composite resins (Oskoee et al., 2009). In our study, two different materials, namely polyethylene fibre sheet (Ribbond THM; Ribbond Inc., Seattle WA, USA) and a fibre glass net (Everstick NET, GC Europe, Leuven, Belgium) were used in different positions inside the cavity with the aim of stabilizing the opposing walls and reinforcing the tooth structure. Polyethylene fibres possess a dense concentration of fixed nodal intersections that assist in maintaining the integrity of the fabric. This enables the stresses in the bulk of the material to be transferred more effectively because of the well-defined load paths from one area to another (Akman et al., 2011). As shown by Eskitascioglu et al., using polyethylene fibre ribbon in combination with bonding agent and flowable composite under composite restoration may act as a stress-absorber due to its lower elastic modulus (Eskitaşcioğlu et al., 2002). In our study, the efficacy of polyethylene fibres in in most groups did not depend on their position within the direct restoration as there was no statistically significant difference among their fracture resistance values. This is in accordance with Akman et al. who did not find significant difference when restoring root canal treated teeth with MOD cavities using polyethylene fibres in different configurations and positions (Akman et al., 2011). In our study, the only exception was between Group 7 and Group $11(p=0.026)$ among the groups with polyethylene fibres. The use of these fibres seems to be beneficial since groups with polyethylene fibres did not differ significantly from the intact teeth, whereas teeth restored with composite alone showed significantly weaker fracture resistance compared to intact teeth $(p=0.033)$. This is contrast to the findings of Belli et al., 2005, 2006b. However, it must be considered that they tested the polyethylene fibres in root canal treated teeth.

It was shown by Garoushi et al. that the addition of continuous bidirectional or short random FRC substructure under composite resin, the load-bearing capacity of the restorations could be increased (Garoushi et al., 2006a,b). Bidirectional fibres within the fibre glass net give orthotropic properties to the material (Başaran et al., 2013). Turkaslan et al. found that pre-impregnated bidirectional FRC can reinforce the tooth interface in two directions, distributing the stresses more evenly and increasing the toughness of the restoration by preventing crack propagation (Turkaslan et al., 2009). So far EverStick NET has only been used beneath endocrowns and anterior veneers, but not in posterior cavities. Contrary to polyethylene fibres, the reinforcing efficacy of bidirectional fibre glass net does seem to vary with its position within the restoration. Group 3 showed significantly reduced fracture resistance compared to Group $5(p=0.001)$ and Group $6(p=0.000)$, while Group 4 was significantly weaker than Group $6(p=0.023)$. While using polyethylene fibres was beneficial in all groups, fibre glass net could efficiently reinforce teeth only in Groups 5 and 6 (no significant difference from control). Interestingly, in specific positions, namely when applied bucco-lingually on the base of the cavity (Groups 3 and 7) or bucco-lingually in the coronal third of the restoration (Groups 4 and 8), the two different bidirectional materials yielded different reinforcement. Groups 3 and 4 were significantly weaker than Group 7 $(p=0.009)$ and Group $8(p=0.049)$, respectively. This could be attributed to the difference in the quality and quantity of fibres. Of all restored groups, Group 3 was characterised by the poorest results. This is in line with the findings of Oskoee et al. (2009). Also, Group 7 (polyethylene fibres laid down on the base of the cavity, connecting the opposing walls) was found to be the weakest among the polyethylene fibre groups. The reason behind this could be that although the opposing walls are connected but the fibres are not streched and not under tension at all. Previous studies have pointed out that the placement of fibres at the tensile side of CR specimens improves flexure properties (Dyer et al., 2004b; Ellakwa et al., 2001).

According to the results of Oskoee et al., placing a glass fibre net as occlusal splinting in the occlusal third of the MOD cavities between composite layers significantly increases fracture resistance (Oskoee et al., 2009). In groups having occlusal splinting the extension of the fibre ends through the occlusal one-third of the buccal or lingual walls allowing the fibre to keep the cusps together, as described by Oskolee et al. (Oskoee et al., 2009) and Akman et al. (2011)

In our study, regardless of which fibre type was used, fibres applied as occlusal splinting resulted in increased fracture resistance and did not differ significantly from intact teeth. This is only partly in accordance with Belli et al. who managed to show increased fracture resistance with occlusally splinted groups with polyethylene fibres. Still, their restored specimens were significantly weaker than intact teeth (Belli et al., 2006b). With occlusal splinting, fibres are placed close to the point where force is exerted, which leads to a shorter working arm according to the principles of levers. In addition, placing fibres on the occlusal surfaces keeps buccal and lingual cusps together, leading to higher fracture resistance (Oskoee et al., 2009). 
Connecting the remaining opposing cavity walls can be also accomplished circumferentially covering the rebuilt mesial and/or distal walls, a technique called "wallpapering" by Deliperi and colleagues (Deliperi et al., 2017). So far, to use of FRC materials to circumferencially connect the walls of MOD cavities was only attempted by Daher et al. (2016), but they performed this externally, around the coronal part of the teeth. In our study, when applied circumferentially, there was no difference between the fibre glass net and polyethylene fibres. Intriguingly, the net applied circumferentially (Group 6) yielded significantly higher fracture resistance than fibre glass net at the base of the cavity (Group 3, $p=0.000$ ) or in the occlusal third inside the filling (Group 4, $p=0.023$ ). At the same time, there was no statistically significant difference between the corresponding Ribbond groups (between Group 7,8,9 and 10). Also, it is worth mentioning that fibre glass net together with SFRC in occlusal splinting (Group 5) or circumferencially (Group 6) was not significantly better than SFRC alone (Group 2) in terms of reinforcement. We assume that even when SFRC is used alone as a dentine substitution, the randomly oriented fibres lend an isotropic reinforcement effect in multiple directions instead of in only a few specific directions (Garoushi et al., 2007b). Also, the adaptation of SFRC alone could be better to the cavity walls. From a clinical point of view it is worth mentioning that the usage of SFRC alone in a bulk manner was easier and less time consuming compared to using the fibre net or the polyethylene one.

Among all restored groups the transcoronal splinting with polyethylene fibres (Group 11) produced the highest fracture resistance, even slightly exceeding the values of intact teeth. In our opinion, this can be attributed to the fact that the polyethylene fibres are not laid down, like in the other groups, but rather stretched, and put under tension. A similar concept was shown by Karzoun et al. with a FRC post penetrating through the opposing walls (Karzoun et al., 2015). As the polyethylene fibres are positioned to the occlusal third of the crown, it should theoretically hold all benefits as the occlusal splinting group, namely working as an early stress-redirecting layer and producing a shorter working arm under loading. Also, the concept is considered to be correct biomechanically as polyethylene fibres, due to their inherent dense network of locked nodal intersections, could also serve as a potential crack stopping mechanism, therefore could attempt to act as a potential DEJ substituting layer.

Regarding fracture pattern, in most cases when fibres were incorporated into the direct restoration, the failure was dominantly a favourable one (above the CEJ). The highest ratio of favourable fractures was seen with SFRC alone (Group 2), whereas composite alone (Group 1) and transcoronal splinting (Group 11) yielded the highest ratio of unfavourable fractures. This, again, points to the increasingly recognized problem of large direct composite restorations, that is, that their fracture toughness is suboptimal, and they cannot serve as a good substitute for DEJ. This way, cracks and fractures propagate freely in them, which, ultimately, results in non-restorable damage.

The limitations of this investigation is that static load to fracture test was used to determine maximal fracture resistance instead of applying cyclic loading. According to Taha et al., "In experimental studies, fracture resistance to static loading has been used as a measure of the effect of cavity preparation and/or restoration on tooth strength. Although the fracture load is typically much higher than functional occlusal loads, it is still a valid method for comparing restorative materials and different cavity designs." (Taha et al., 2011). Also, as stated by Le Bell-Rönnlöf et al., static loading is usually the first step in the evaluation process of a novel dental materials and related techniques and is commonly used in order to obtain basic knowledge regarding the fracture behaviour and load capacity of a post restored tooth (Le Bell-Rönnlöf et al., 2011). Given the mentioned shortcomings, the proposed techniques should require future testing with cyclic dynamic loading.

\section{Conclusions}

1. Deep MOD cavities in non-root canal treated molars can be reinforced with fibres utilized in direct restorative techniques.

2. The use of polyethylene fibres seems to be always beneficial, regardless of position within the cavity or the restoration.

3. The efficacy of glass fibre net together with SFRC, regarding fracture resistance, is highly dependent on their position within the cavity or in the restoration.

4. Bulk-applied SFRC (to substitute dentine and the DEJ) covered with composite can reinforce deep MOD cavities in non-root canal treated molars.

5. If fracture happens with direct composite restorations in deep MOD cavities in non-root canal treated molars, it is predominantly an unfavourable (irreparable) fracture.

\section{Conflicts of interests}

All authors declare to have no conflict of interests.

\section{Acknowledgments}

This study was supported by the UNKP-18-3 New National Excellence Program of The Ministry of Human Capacities.

\section{References}


Akman, S., Akman, M., Eskitascioglu, G., Belli, S., 2011 May. Influence of several fibre-reinforced composite restoration techniques on cusp movement and fracture strength of molar teeth. Int. Endod. J. 44 (5), 407-415. doi:10.1111/j.13652591.2010.01843.x.

Ástvaldsdóttir, Á., Dagerhamn, J., van Dijken, J.W., Naimi-Akbar, A., Sandborgh-Englund, G., Tranæus, S., Nilsson, M., 2015. Longevity of posterior resin composite restorations in adults - a systematic review. J. Dent. 43 (8), 934-954. doi:10.1016/j.jdent.2015.05.001 (Aug).

Başaran, E.G., Ayna, E., Vallittu, P.K., Lassila, L.V., 2013 Feb. Load bearing capacity of fiber-reinforced and unreinforced composite resin CAD/CAM-fabricated fixed dental prostheses. J. Prosthet. Dent 109 (2), 88-94. doi:10.1016/S00223913(13)60022-0.

Behery, H., El-Mowafy, O., El-Badrawy, W., Saleh, B., Nabih, S., 2016. Cuspal deflection of premolars restored with bulk-fill composite resins. J. Esthetic Restor. Dent. 28 (2), 122-130. doi:10.1111/jerd.12188 (Mar-Apr).

Belli, S., Erdemir, A., Ozcopur, M., Eskitascioglu, G., 2005 Feb. The effect of fibre insertion on fracture resistance of root filled molar teeth with MOD preparations restored with composite. Int. Endod. J. 38 (2), 73-80 (PubMed PMID: 15667628).

Belli, S., Dönmez, N., Eskitaşcioğlu, G., 2006 Aug. The effect of c-factor and flowable resin or fiber use at the interface on microtensile bond strength to dentin. J. Adhesive Dent. 8 (4), 247-253 (PubMed PMID: 16958290).

Belli, S., Erdemir, A., Yildirim, C., 2006 Feb. Reinforcement effect of polyethylene fibre in root-filled teeth: comparison of two restoration techniques. Int. Endod. J. 39 (2), 136-142 (PubMed PMID: 16454794).

Bijelic-Donova, J., Garoushi, S., Vallittu, P.K., Lassila, L.V., 2016. Mechanical properties, fracture resistance, and fatigue limits of short fiber reinforced dental composite resin. J. Prosthet. Dent 115, 95-102. doi:10.1016/j.prosdent.2015.07.012.

Braga, R.R., Boaro, L.C., Kuroe, T., Azevedo, C.L., Singer, J.M., 2006 Sep. Influence of cavity dimensions and their derivatives (volume and ' $C$ ' factor) on shrinkage stress development and microleakage of composite restorations. Dent. Mater. 22 (9), 818-823 (Epub 2005 Dec 20. PubMed PMID: 16368130).

Cara, R.R., Fleming, G.J., Palin, W.M., Walmsley, A.D., Burke, F.J., 2007 Jun. Cuspal deflection and microleakage in premolar teeth restored with resin-based composites with and without an intermediary flowable layer. J. Dent. 35 (6), $482-489$ (Epub 2007 Feb 23. PubMed PMID: 17321029).

Chai, H., Lawn, B.R., 2017 Jul. Fracture resistance of molar teeth with mesial-occlusal-distal (MOD) restorations. Dent. Mater. 33 (7), e283-e289. doi:10.1016/j.dental.2017.04.019.

Cobankara, F.K., Unlu, N., Cetin, A.R., Ozkan, H.B., 2008 Sep-Oct. The effect of different restoration techniques on the fracture resistance of endodontically-treated molars. Operat. Dent. 33 (5), 526-533. doi:10.2341/07-132.

Daher, R., Feilzer, A.J., Krejci, I., 2016 Nov. Novel non-invasive reinforcement of MOD cavities on endodontically treated teeth. J. Dent. 54, 77-85. doi:10.1016/j.jdent.2016.09.008.

de V Habekost, L., Camacho, G.B., Azevedo, E.C., Demarco, F.F., 2007 Sep. Fracture resistance of thermal cycled and endodontically treated premolars with adhesive restorations. J. Prosthet. Dent 98 (3), 186-192 (PubMed PMID: 17854619).

Deliperi, S., Alleman, D., Rudo, D., 2017. Stress-reduced direct composites for the restoration of structurally compromised teeth: fiber design according to the "wallpapering" technique. Operat. Dent. 42 (3), 233-243. doi:10.2341/15-289-T (May/Jun)

Demarco, F.F., Corrêa, M.B., Cenci, M.S., Moraes, R.R., Opdam, N.J., 2012 Jan. Longevity of posterior composite restorations: not only a matter of materials. Dent. Mater. 28 (1), 87-101. doi:10.1016/j.dental.2011.09.003.

Dyer, S.R., Lassila, L.V., Jokinen, M., Vallittu, P.K., 2004 Dec. Effect of fiber position and orientation on fracture load of fiberreinforced composite. Dent. Mater. 20 (10), 947-955 (PubMed PMID: 15501323).

Dyer, S.R., Lassila, L.V., Jokinen, M., Vallittu, P.K., 2004 Dec. Effect of fiber position and orientation on fracture load of fiberreinforced composite. Dent. Mater. 20 (10), 947-955 (PubMed PMID: 15501323).

El-Helali, R., Dowling, A.H., McGinley, E.L., et al., 2013. Influence of resin-based composite restoration technique and endodontic access on cuspal deflection and cervical microleakage scores. J. Dent. 41, $216-222$. doi:10.1016/j.jdent.2012.11.002. 
Ellakwa, A.E., Shortall, A.C., Shehata, M.K., Marquis, P.M., 2001 Aug. The influence of fibre placement and position on the efficiency of reinforcement of fibre reinforced composite bridgework. J. Oral Rehabil. 28 (8), $785-791$ (PubMed PMID: 11556961).

Eskitaşcioğlu, G., Belli, S., Kalkan, M., 2002 Sep. Evaluation of two post core systems using two different methods (fracture strength test and a finite elemental stress analysis). J. Endod. 28 (9), 629-633 (PubMed PMID: 12236304).

FDI World Dental Federation, 2014. FDI policy statement on dental amalgam and the minamata convention on mercury: adopted by the FDI general assembly: 13 september 2014, New Delhi, India. Int. Dent. J. 64 (6), 295-296. doi:10.1111/idj.12151 (Dec).

Forster, A., Braunitzer, G., Tóth, M., Szabó, B.P., Fráter, M., 2019 Jan. In vitro fracture resistance of adhesively restored molar teeth with different MOD cavity dimensions. J. Prosthodont. 28 (1), e325-e331. doi:10.1111/jopr.12777.

Fráter, M., Forster, A., Keresztúri, M., Braunitzer, G., Nagy, K., 2014 Sep. In vitro fracture resistance of molar teeth restored with a short fibre-reinforced composite material. J. Dent. 42 (9), 1143-1150. doi:10.1016/j.jdent.2014.05.004.

Garoushi, S., Lassila, L.V., Tezvergil, A., Vallittu, P.K., 2006. Load bearing capacity of fibre-reinforced and particulate filler composite resin combination (Mar). J. Dent. 34 (3), 179-184 (Epub 2005 Sep 8. PubMed PMID: 16150524).

Garoushi, S.K., Lassila, L.V., Vallittu, P.K., 2006. Fiber-reinforced composite substructure: load-bearing capacity of an onlay restoration. Acta Odontol. Scand. 64, 281-285 (PubMed PMID: 16945893).

Garoushi, S., Vallittu, P.K., Lassila, L., 2007. Direct restoration of severely damaged incisors using short fiber-reinforced composite resin. J. Dent. 35, 731-736 (Epub 2007 Jul 5. PubMed PMID: 17614187).

Garoushi, S., Vallittu, P.K., Lassila, L.V., 2007. Fracture resistance of short, randomly oriented, glass fiber-reinforced composite premolar crowns (Sep). Acta Biomater. 3 (5), 779-784 (Epub 2007 Apr 8. PubMed PMID: 17420162).

Garoushi, S., Lassila, L.V.J., Tezvergil, A., Vallittu, P.K., 2007. Static and fatigue compression test for particulate filler composite resin with fiber-reinforced composite substructure. Dent. Mater. 23, 17-23 (Epub 2006 Jan 18. PubMed PMID: 16414110).

Garoushi, S., Mangoush, E., Vallittu, M., Lassila, L., 2013 Dec 30. Short fiber reinforced composite: a new alternative for direct onlay restorations. Open Dent. J. 7, 181-185. doi:10.2174/1874210601307010181.

Garoushi, S., Säilynoja, E., Vallittu, P.K., Lassila, L., 2013 Aug. Physical properties and depth of cure of a new short fiber reinforced composite. Dent. Mater. 29 (8), 835-841. doi:10.1016/j.dental.2013.04.016.

Garoushi, S., Gargoum, A., Vallittu, P.K., Lassila, L., 2018 Aug. Short fiber-reinforced composite restorations: a review of the current literature. J. Investig. Clin. Dent. 9 (3). doi:10.1111/jicd.12330, e12330.

Hannig, C., Westphal, C., Becker, K., et al., 2005. Fracture resistance of endodontically treated maxillary premolars restored with CAD/CAM ceramic inlays. J. Prosthet. Dent 94, 342-349 (PubMed PMID: 16198171).

Karzoun, W., Abdulkarim, A., Samran, A., Kern, M., 2015 Jun. Fracture strength of endodontically treated maxillary premolars supported by a horizontal glass fiber post: an in vitro study. J. Endod. 41 (6), 907-912. doi:10.1016/j.joen.2015.01.022.

Kielbassa, A.M., Lynch, C.D., Wilson, N.H., 2014 Jul-Aug. Editorial: the Minamata convention: the beginning of the (amalgam-free) future?. Quintessence Int. 45 (7), 547-548. doi:10.3290/j.qi.a32032.

Lassila, L., Keulemans, F., Säilynoja, E., Vallittu, P.K., Garoushi, S., 2018 Apr. Mechanical properties and fracture behavior of flowable fiber reinforced composite restorations. Dent. Mater. 34 (4), 598-606. doi:10.1016/j.dental.2018.01.002.

Le Bell-Rönnlöf, A.M., Lassila, L.V., Kangasniemi, I., Vallittu, P.K., 2011 Jun. Load-bearing capacity of human incisor restored with various fiber-reinforced composite posts. Dent. Mater. 27 (6), e107-e115. doi:10.1016/j.dental.2011.02.009.

Lee, J.J., Kwon, J.Y., Chai, H., Lucas, P.W., Thompson, V.P., Lawn, B.R., 2009 Mar. Fracture modes in human teeth. J. Dent. Res. 88 (3), 224-228. doi:10.1177/0022034508330055.

Monaco, C., Bortolotto, T., Arena, A., Krejci, I., 2015 Dec. Restoring nonvital premolars with composite resin onlays: effect of different fiber-reinforced composite layers on marginal adaptation and fracture load. J. Adhesive Dent. 17 (6), $567-574$. doi:10.3290/j.jad.a35251.

Oskoee, P.A., Ajami, A.A., Navimipour, E.J., Oskoee, S.S., Sadjadi, J., 2009 Mar. The effect of three composite fiber insertion techniques on fracture resistance of root-filled teeth. J. Endod. 35 (3), 413-416. doi:10.1016/j.joen.2008.11.027. 
Papadopoulos, C., Dionysopoulos, D., Tolidis, K., Kouros, P., Koliniotou-Koumpia, E., Tsitrou, E.A., 2018 Nov 16. Structural integrity evaluation of large MOD restorations fabricated with a bulk-fill and a CAD/CAM resin composite. Mater. Oper. Dent.. doi:10.2341/18-013-L.

Plotino, G., Buono, L., Grande, N.M., Lamorgese, V., Somma, F., 2008 Mar. Fracture resistance of endodontically treated molars restored with extensive composite resin restorations. J. Prosthet. Dent 99 (3), 225-232. doi:10.1016/S00223913(08)60047-5.

Reeh, E.S., Douglas, W.H., Messer, H.H., 1989. Stiffness of endodontically-treated teeth related to restoration technique. J. Dent. Res. 68, 1540-1544 (PubMed PMID: 2584522).

Rocca, G.T., Saratti, C.M., Poncet, A., Feilzer, A.J., Krejci, I., 2016 May. The influence of FRCs reinforcement on marginal adaptation of CAD/CAM composite resin endocrowns after simulated fatigue loading. Odontology 104 (2), $220-232$. doi:10.1007/s10266-015-0202-9.

Rudo, D.N., Karbhari, V.M., 1999 Jan. Physical behaviors of fiber reinforcement as applied to tooth stabilization. Dent. Clin. N. Am. 43 (1), 7-35 (v. PubMed PMID: 9929797).

Scholtanus, J.D., Ozcan, M., 2014 Nov. Clinical longevity of extensive direct composite restorations in amalgam replacement: up to 3.5 years follow-up. J. Dent. 42 (11), 1404-1410. doi:10.1016/j.jdent.2014.06.008.

Scotti, N., Coero Borga, F.A., Alovisi, M., et al., 2012. Is fracture resistance of endodontically treated mandibular molars restored with indirect onlay composite restorations influenced by fiber post insertion?. J. Dent. 40, 814-820. doi:10.1016/j.jdent.2012.06.005.

Seo, D.G., Yi, Y.A., Shin, S.J., et al., 2012. Analysis of factors associated with cracked teeth. J. Endod. 38, $288-292$. doi:10.1016/j.joen.2011.11.017.

Soares, C.J., Martins, L.R., Pfeifer, J.M., Giannini, M., 2004. Fracture resistance of teeth restored with indirect-composite and ceramic inlay systems. Quintessence Int. 35 4, 281-286 (PubMed PMID: 15119713).

Soares, P.V., Santos-Filho, P.C., Martins, L.R., Soares, C.J., 2008 Jan. Influence of restorative technique on the biomechanical behavior of endodontically treated maxillary premolars. Part I: fracture resistance and fracture mode. J. Prosthet. Dent 99 (1), 30-37. doi:10.1016/S0022-3913(08)60006-2.

Taha, N.A., Palamara, J.E., Messer, H.H., 2009 Sep. Cuspal deflection, strain and microleakage of endodontically treated premolar teeth restored with direct resin composites. J. Dent. 37 (9), 724-730. doi:10.1016/j.jdent.2009.05.027.

Taha, N.A., Palamara, J.E., Messer, H.H., 2011 Aug. Fracture strength and fracture patterns of root filled teeth restored with direct resin restorations. J. Dent. 39 (8), 527-535. doi:10.1016/j.jdent.2011.05.003.

Turkaslan, S., Tezvergil-Mutluay, A., Bagis, B., Vallittu, P.K., Lassila, L.V., 2009. Effect of fiber-reinforced composites on the failure load and failure mode of composite veneers. Dent. Mater. J. 28, 530-536 (PubMed PMID: 19822982).

Vallittu, P.K., 1998 Feb. The effect of glass fiber reinforcement on the fracture resistance of a provisional fixed partial denture. J. Prosthet. Dent 79 (2), 125-130 (PubMed PMID: 9513095).

Vallittu, P.K., 2002 May. Use of woven glass fibres to reinforce a composite veneer. A fracture resistance and acoustic emission study. J. Oral Rehabil. 29 (5), 423-429 (PubMed PMID: 12028488).

Vallittu, P.K., 2015. High-aspect ratio fillers: fiber-reinforced composites and their anisotropic properties. Dent. Mater. 31, 1-7. doi:10.1016/j.dental.2014.07.009.

Wu, Y., Cathro, P., Marino, V., 2010 Nov. Fracture resistance and pattern of the upperpremolars with obturated canals and restored endodontic occlusal access cavities. J. Biomed. Res. 24 (6), 474-478. doi:10.1016/S1674-8301(10)60063-2.

\section{Highlights}

- Deep MOD cavities in vital molars can be reinforced with fibre-reinforced direct restorations.

- Polyethylene fibres increase fracture resistance regardless of its position in the restoration.

- Short fibre-reinforced composite is able to act as a stress-absorbing core inside the filling. 


\section{Queries and Answers}

Query: Your article is registered as a regular item and is being processed for inclusion in a regular issue of the journal. If this is NOT correct and your article belongs to a Special Issue/Collection please contact t.gunasekaran.1@elsevier.com immediately prior to returning your corrections.

Answer: Yes

Query: Please confirm that the provided email "meddentist.fm@gmail.com" is the correct address for official communication, else provide an alternate e-mail address to replace the existing one, because private e-mail addresses should not be used in articles as the address for communication.

Answer: yes, this email is correct.

Query: Please confirm that given names and surnames have been identified correctly and are presented in the desired order and please carefully verify the spelling of all authors' names.

Answer: Yes

Query: Please note that author's telephone/fax numbers are not published in Journal articles due to the fact that articles are available online and in print for many years, whereas telephone/fax numbers are changeable and therefore not reliable in the long term.

Answer: all right.

Query: Here we have received the citation of "Group 12", but the corresponding content(Group 12) is missing. So, please provide the content of Group 12.

Answer: As Group 12 is a control group (healthy teeth), the required content is just in the beginning og 2.1 cavity preparation and restorative procedures section in the first line.

Query: Please Check the Figure caption(2 to 4).

Answer: perfect.

Query: Bijelic-Donova et al., 2016b cited in the text and list has been changed to BijelicDonova et al., 2016 because there is only one citation of "Bijelic-Donova et al., 2016" in the article. Please check, and correct if necessary.

Answer: yes, thank you for your correction.

Query: In the reference list Garoushi et al., 2006a and 2006b are mentioned as separate references. Therefore we have changed all citations of Garoushi et al., 2006 to Garoushi et al., 2006a,b. Please amend the citations in the text if necessary.

Answer: it is fine this way.

Query: Have we correctly interpreted the following funding source(s) you cited in your article: New National Excellence Program of The Ministry of Human Capacities?

Answer: Yes 
